\title{
Power Quality Improvement in Distribution Line Using D-STATCOM
}

\author{
Nipun Paroha ${ }^{1}$, Vivek Anand ${ }^{2}$
}

\begin{abstract}
A Power quality means maintain the sinusoidal bus voltage at rated frequency. A power quality problem is an occurrence manifested as a nonstandard voltage, current or frequency that results in a failure or a mis-operation of end user equipments. This paper purpose a noval distribution level voltage control scheme that can compensate voltage sag and swell condition in distribution system. DSTATCOM is one of the equipments for voltage sag/swell mitigation in power systems. Voltage sag has been considered as one of the most harmful power quality problem as it may significantly affect industrial production. This paper presents power quality improvement in Distribution line using Distribution Static Compensator (D-STATCOM) to mitigate voltage sag under faults. Voltage sag under different type of short circuits has been estimated using MATLAB/SIMULINK software.
\end{abstract}

Keywords: D-STATCOM, Total harmonics Distortion (THD, Voltage Sag/swell, Voltage Source Converter (VSC)

\section{Introduction}

Power quality is a young challenging subject was introduced in the early1979. The term power quality has been used to describe the variation of the voltage current and frequency on the power system. The demand for better power quality is increasing with the use of control and equipment in industrial, commercial, institutional and government facilities, the continuity, reliability and quality of electric services has become extremely important to give attention to power quality. The power quality can be degraded by use of nonlinear loads and semiconductor switching devices. Power disturbance such as voltage sags well, transient and harmonics can destroy or shorten the life of sensitive equipment. The voltage sag or swell is a serious power quality that exists today. The voltage sag/swell magnitude is ranged from $10 \%$ to $90 \%$ of nominal voltage and with duration from half a cycle to $1 \mathrm{~min}$. In a three phase system voltage sag is by nature a three-phase phenomenon, which affects both the phase-to-ground and phase-to-phase voltages. Voltage sag is caused by a fault in the utility system, a fault within the customer's facility or a large increase of the load current, like starting a motor or transformer energizing. Typical faults are single-phase or multiple-phase short circuits, which leads to high currents. The high current results in a voltage drop over the network impedance. Many efforts have been made to solve the situation, the latest technology is based on power electronics. Modern semiconductor switching devices are being utilized more and more in a wide range of applications in distribution network particularly in domestic and industrial loads. Among these, the D-STATCOM is one of the most effective device is based on the voltage source converter principle. The D-STATCOM has additional capability to sustain reactive current at low voltage, and can be developed as a voltage and frequency support by replacing capacitors with batteries as energy storage. To enhance the power quality such as voltage sags/swell, harmonic distortion and low power factor in distribution system. The aim therefore in this work is identify the power quality problems and thereby to recommend measures that can enhance the quality of power.

\section{Voltage Source Converter (VSC)}

A voltage-source converter is a power electronic device, it is the core component of the STATCOM. During voltage dips, VSC generates proper voltage and introduces a voltage difference between the VSC and the point of connection with the power system. VSC can generate a sinusoidal voltage with any required magnitude, frequency and phase angle. Voltage source converters are forced-commutated converter that converts ac voltage into dc voltage and vice versa. The power can flow through the VSC in any direction and from the ac terminals. It can be considered as a controllable voltage source. VSC is used to either completely replace the voltage or to inject the 'missing voltage'. The 'missing voltage' is the difference between the nominal voltage and the actual. The converter is normally based on some kind of energy storage, which will supply the converter with a DC voltage. The solid-state electronics in the converter is then switched to get the desired output voltage. Normally the VSC is not only used for voltage sag/swell mitigation, but also for other power quality issues, e.g. flicker and harmonics.

\section{Energy Storage Circuit}

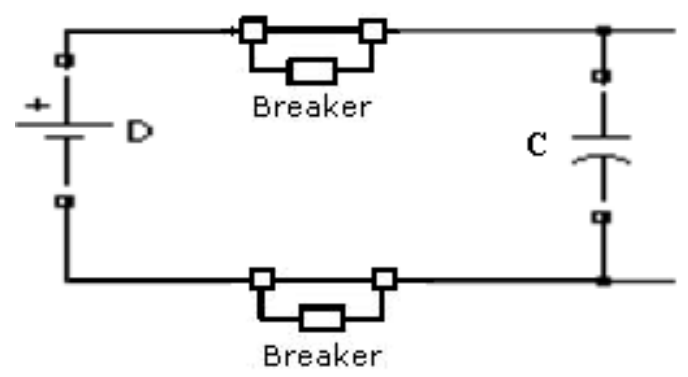

Figure 3.1: Circuit Diagram of DC Storage

From fig 3.1 DC source is connected in parallel with the DC capacitor. The purpose of energy storage is to maintain the dc side voltage of VSC. It carries the input ripple current of the converter and it is the main reactive energy storage element. This DC capacitor could be charged by a battery source or could be recharged by the converter itself. 


\section{International Journal of Science and Research (IJSR) \\ ISSN (Online): 2319-7064}

Index Copernicus Value (2013): 6.14 | Impact Factor (2015): 6.391

\section{Controller}

The controller executes the calculation of the correct output voltage of VSC which leads to proper shunt compensation current and PWM modulation. The aim of the control scheme is to maintain constant voltage magnitude at the point where a sensitive load is connected, under system disturbances. The control system only measures the r.m.s voltage at the load point, i.e., no reactive power measurements are required. The VSC switching strategy is based on a sinusoidal PWM technique which offers simplicity and good response. Since custom power is a relatively low-power application, PWM methods offer a more flexible option than the Fundamental Frequency Switching (FFS) methods favored in FACTS applications. Besides, high switching frequencies can be used to improve on the efficiency of the converter, without incurring significant switching losses.

The controller input is an error signal obtained from the reference voltage and the value rms of the terminal voltage measured. Such error is processed by a PI controller the output is the angle $\delta$, which is provided to the PWM signal generator. It is important to note that in this case, indirectly controlled converter, there is active and reactive power exchange with the network simultaneously: an error signal is obtained by comparing the reference voltage with the rms voltage measured at the load point. The PI controller process the error signal generates the required angle to drive the error to zero, i.e., the load rms voltage is brought back to the reference voltage.

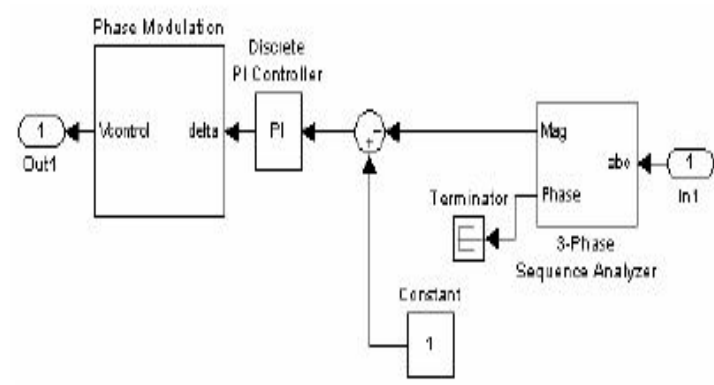

Figure 4.1: Simulink Model of D-STATCOM Controller

\section{Distribution \\ Static (DSTATCOM) \\ Compensator}

A D-STATCOM (Distribution Static Compensator), which is schematically depicted in Figure-5.1, The D-STATCOM is a three phase and shunt connected power electronics based reactive power compensation equipment which can generates and absorbs the reactive power whose output can be varied so as to maintain control of specific parameters of the electric power system. It consists of a two-level Voltage Source Converter (VSC), a dc energy storage device, a coupling transformer connected in shunt to the distribution network through a coupling transformer. The D-STATCOM employs an inverter to converts the dc link voltage $\mathrm{Vdc}$ on the capacitor to a voltage source of adjustable magnitude and phase. The VSC converts the dc voltage across the storage device into a set of three-phase ac output voltages. These voltages are in phase and coupled with the ac system through the reactance of the coupling transformer. Suitable adjustment of the phase and magnitude of the D-STATCOM output voltages allows effective control of active and reactive power exchanges between the D-STATCOM and the ac system. Such configuration allows the device to absorb or generate controllable active and reactive power.

The operation of DSTATCOM is as follows: the voltage is compared with the AC bus voltage system(Vs).

- When the AC bus voltage magnitude is above that of the VSI voltage magnitude (Vc),the AC system sees the DSTATCOM as inductance connected to its terminals.

- Otherwise if the VSI voltage magnitude is above that of the AC bus voltage magnitude, the AC system sees the DSTATCOM as capacitance to its terminals.

- If the voltage magnitudes are equal, the reactive power exchange is zero. The value of Ish can be controlled by adjusting the output voltage of the converter. The shunt injected current Ish can be written as,

$I_{s h}=I_{L}-I_{S}=I_{L}-\frac{V_{\text {th }}-V_{L}}{Z_{\text {th }}}$
$I_{s h} \angle \eta=I_{L} \angle-\theta-\frac{V_{\text {th }}}{Z_{\text {th }}} \angle(\delta-\beta)+\frac{V_{L}}{Z_{\text {th }}} \angle-\beta$

$\mathrm{I}_{\text {out }}=$ output current $\mathrm{I}_{\mathrm{L}}=$ load current

$\mathrm{I}_{\mathrm{S}}=$ source current $\mathrm{V}_{\text {th }}=$ thevenin voltage

$\mathrm{V}_{\mathrm{L}}=$ load voltage $\mathrm{Z}_{\text {th }}=$ impedence

Referring to the equation 5.1, output current, will correct the voltage sags by adjusting the voltage drop across the system impedance, $(\mathrm{Z}$ th $=\mathrm{R}+\mathrm{j} \mathrm{X})$.

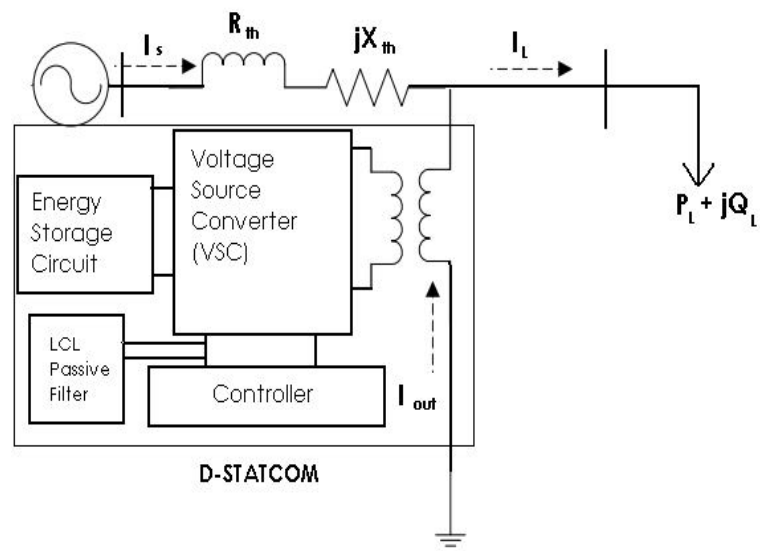

Figure 5.1: Schematic Diagram of D-STATCOM

\section{Methodology}

To enhance the performance of distribution system, DSTATCOM was connected to the distribution system. DSTATCOM was designed using MATLAB simulink version $\mathrm{R} 2009 \mathrm{~b}$. The test system shown in figure 6.1 comprises a $230 \mathrm{kV}, 50 \mathrm{~Hz}$ transmission system, feeding into the primary side of a 3-winding transformer connected in $\mathrm{Y} / \mathrm{Y} / \mathrm{Y}$, $230 / 11 / 11 \mathrm{kV}$. A varying load is connected to the $11 \mathrm{kV}$, secondary side of the transformer. A two-level DSTATCOM is connected to the $11 \mathrm{kV}$ tertiary winding to provide instantaneous voltage support at the load point. A

\section{Volume 5 Issue 6, June 2016}




\section{International Journal of Science and Research (IJSR) \\ ISSN (Online): 2319-7064}

Index Copernicus Value (2013): 6.14 | Impact Factor (2015): 6.391

$750 \mu \mathrm{F}$ capacitor on the dc side provides the DSTATCOM energy storage capabilities. Circuit Breaker is used to control the period of operation of the D-STATCOM.

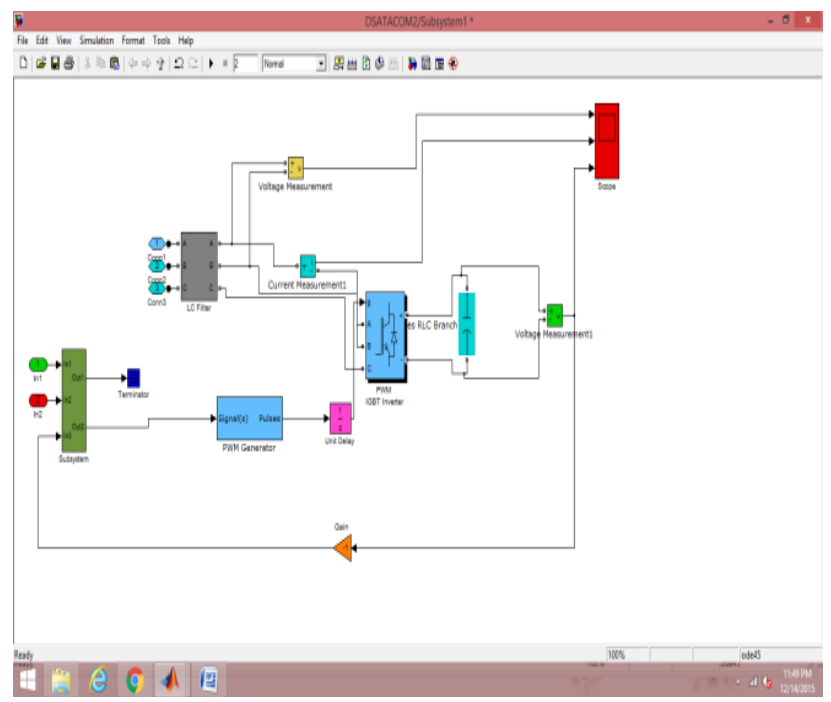

Figure 6.1: Single line Diagram of Test System

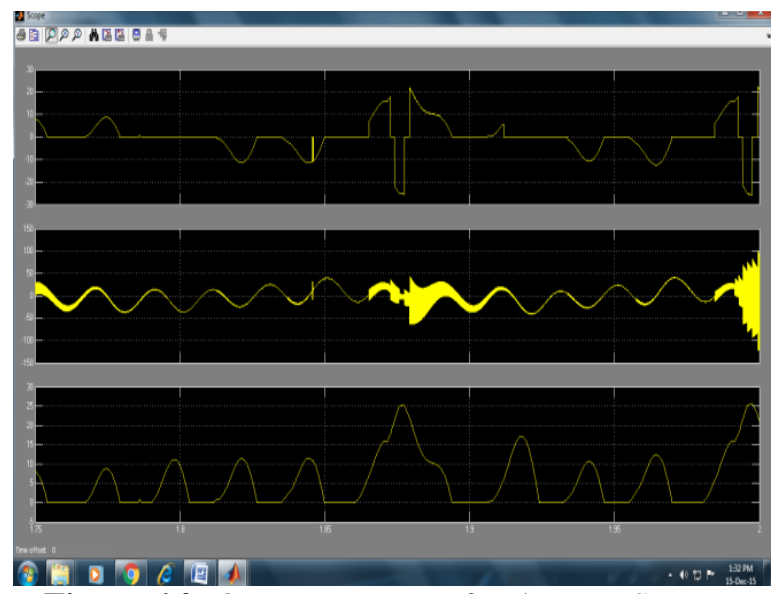

Figure 6.2: Output Response for the Test System

\section{Simulink Model for the Test System}

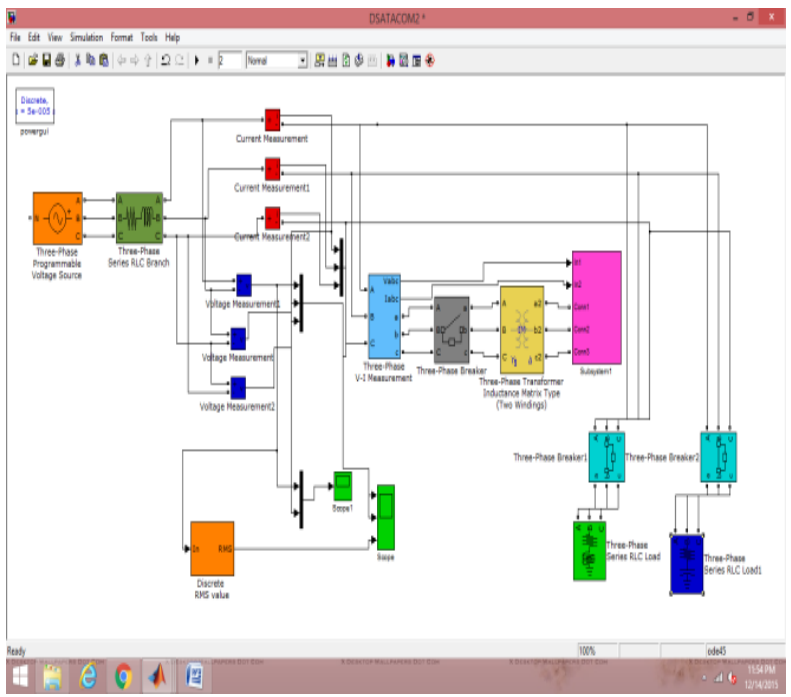

Figure 7.1: Simulink model of D-Statcom with transmission line

\section{Results}

\subsection{Simulation results}

Performance of voltage vrms at load point, with three phase-to-ground fault:

CASE 1. Three phase ground fault without D-STATCOM In the first case simulation contains no D-STATCOM and a three phase-to-ground fault is applied. In this case, DSTATCOM is not connected and output wave for the load without D-STATCOM shown in figure 8.1

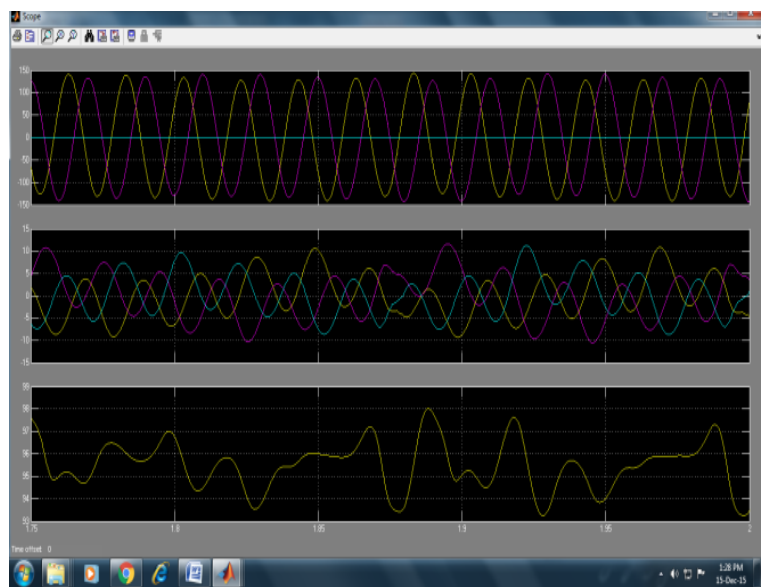

Figure 8.1: Output Response of the Distribution line without D-STATCOM

CASE 2. Three phase-to- ground fault with D-STATCOM The second simulation is carried out using the same scenario, DSTATCOM is connected to the system, then the voltage sag is mitigated almost completely. The output wave for the load with D-STATCOM shown in figure 8.2.

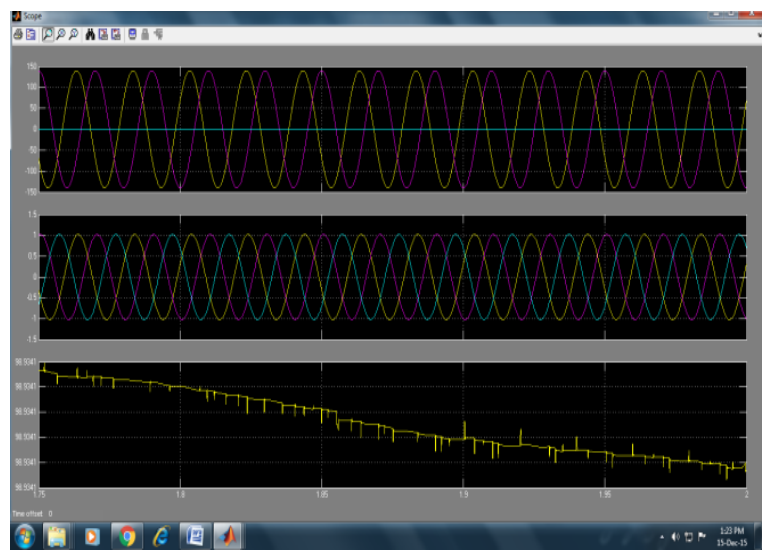

Figure 8.2: Output response of the line with D-STATCOM

\section{Conclusion}

In this work, an attempt is made to find out what types of power quality problems are occurring in distribution system. Among all of them voltage sag in the most common which is stimulated with the help of D-STATCOM. The conclusion is as follows:

- The D-STATCOM protects the utility transmission or distribution system from voltage sag and flicker caused by rapidly varying reactive current demand. During the transient condition the DSTATCOM provides leading or

\section{Volume 5 Issue 6, June 2016} www.ijsr.net 


\section{International Journal of Science and Research (IJSR) \\ ISSN (Online): 2319-7064}

Index Copernicus Value (2013): 6.14 | Impact Factor (2015): 6.391

lagging reactive power to active system stability, power factor correction and load balancing.

- This work presented a study, simulation and behaviour of D-STSTCOM to improve the power quality problems of distribution network. It can be summarized that it is a promising device and helps is mitigating power quality problem.

\section{References}

[1] G. Yaleinkaya, M.H.J. Bollen, P.A. Crossley, "Characterization of voltage sags in industrial distribution systems", IEEE transactions on industry applications, vol.34, no. 4, July/August, pp. 682-688, 1999.

[2] Haque, M.H., "Compensation of distribution system voltage sag by DVR and D-STATCOM", Power Tech Proceedings, 2001 IEEE Porto, vol.1, pp.10-13, Sept. 2001.

[3] Anaya-Lara O, Acha E., "Modeling and analysis of custom power systems by PSCAD/EMTDC", IEEE Transactions on Power Delivery, Vol.17, Issue: 1, Jan. 2002, Pages:266 - 272.

[4] Bollen, M.H.J.," Voltage sags in three-phase systems" Power Engineering Review, IEEE, Vol. 21, Issue: 9, Sept. 2001, pp: 8 - 11, 15.

[5] R.Mienski,R.Pawelek and I.Wasiak., "Shunt Compensation for Power Quality Improvement Using a STATCOM controller: Modelling and Simulation", IEEE Proce., Vol.151, No.2, March 2004.

Volume 5 Issue 6, June 2016 www.ijsr.net 